\title{
Bilateral pulmonary agenesis, oesophageal atresia, and the first arch syndrome
}

\author{
P. J. DEB USE and G. MOR R IS ${ }^{1}$ \\ Departments of Child Health and Pathology, University of Papua, New Guinea
}

\begin{abstract}
DeBuse, P. J., and Morris, G. (1973). Thorax, 28, 526-528. Bilateral pulmonary agenesis, oesophageal atresia, and the first arch syndrome. This is the case report of an infant born alive with absence of both lungs, atresia of the oesophagus, and the first arch syndrome.
\end{abstract}

Absence of both lungs is extremely rare; there appear to be only four recorded cases (Claireaux and Ferreira, 1958 ; Tuynman and Gardner, 1952 ; Allan and Affelbach, 1925; Schmit, 1893). Oesophageal atresia has a frequency of about $1: 3,500$ births and the first arch syndrome is uncommon. The occurrence of all three of these conditions in a liveborn infant has not previously been recorded and it may be important in determining the pathogenesis.

\section{CASE REPORT}

The mother was a Chinese woman aged 29 with three previous pregnancies producing living children-males, 8 and 6 years; female, 5 years. The father was noted to have a moderate degree of micrognathia.

For two years before this pregnancy the mother had been taking an oral contraceptive in an intermittent fashion. From July to September 1971 she had irregular menses. In late November 1971 she thought she was pregnant. In early January 1972 she was in contact with rubella and was given gamma globulin. In February 1972 she received ampicillin for an ear infection. No other record of ill health during pregnancy was obtained. There is no record of polyhydramnios.

The labour was spontaneous and she was delivered of a female infant weighing $2.630 \mathrm{~kg}$. Cyanosis was observed at birth with a heart rate greater than $100 /$ min. The infant made increasing respiratory efforts for 3 to 4 minutes but with no air entry. Attempts at intubation were unsuccessful because of micrognathia, microstomia, and microglossia.

Tracheostomy was considered but the respiratory efforts became less and the heart sounds ceased after 20 minutes.

\section{SUMMARY OF NECROPSY REPORT}

The body was that of a full-term female infant. The jaw and mouth were small; the latter would

1Present address: Pathology Department, St. Vincent's Hospital, Sydney, Australia

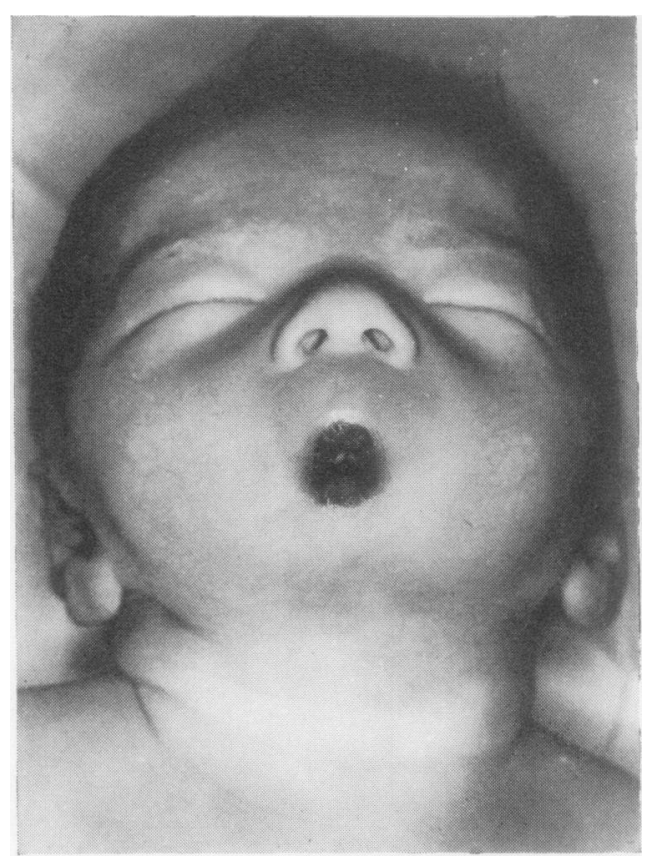

FIG. 1. Microstomia and micrognathia.

admit only one finger (Fig. 1). There were no other congenital abnormalities noted on external inspection. The following abnormalities were noted on internal examination.

(a) The mandible and tongue were small, approximately one-third of the expected size, but anatomically normal and in normal proportion to each other. The nasopharynx, oral cavity, and larynx showed no abnormality. The oesophagus ended blindly approximately $4 \mathrm{~cm}$ distally. There 


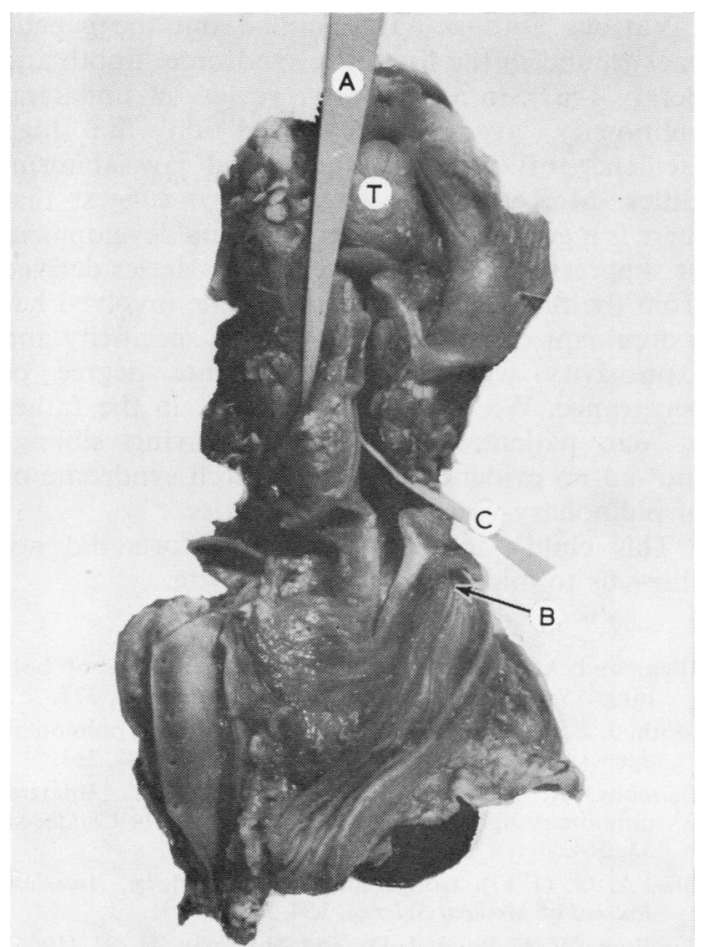

FIG. 2. The trachea and oesophagus seen from behind: $A$ upper oesophagus; (B) lower oesophagus; $(C)$ trachea; (T) tongue.

was no communication with the trachea at this point. The gastric end of the oesophagus joined the posterior aspect of the trachea just above the carina to give a tracheo-oesophageal fistula. The trachea ended in two rudimentary bronchial buds (Fig. 2). The anus was imperforate. The rectum ended blindly beneath the skin surface.

(b) There was complete agenesis of both lungs.

(c) There was no gross intracardiac lesion. The pulmonary artery, which arose from the right ventricle, did not divide into branches and joined the aorta at the site of the ductus arteriosus (Fig. 3).

(d) The left kidney was smaller than the right ( $7 \mathrm{~g}$ as compared to $14 \mathrm{~g}$ ) and was situated in the midline on the pelvic brim with the pelvis facing anteriorly. The uterus was unicornuate. The remainder of the genitourinary system showed no abnormality. The external genitalia were normal.

Histological examination revealed no specific infective process or further abnormality.

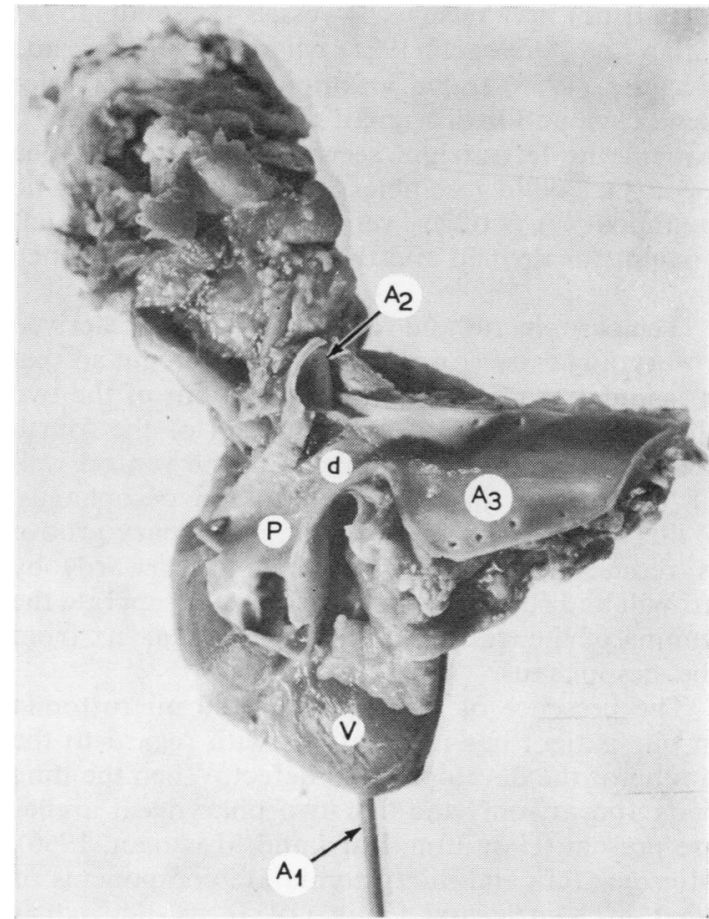

FIG. 3. The heart and great vessels: $\left(A_{1}, A_{2}\right)$ probe from left ventricle into aorta; $\left(A_{3}\right)$ aorta; $(P)$ pulmonary artery; (d) ductus arteriosus.

\section{DISCUSSION}

The potential teratogenic effect of the possible rubella infection in early pregnancy was not confirmed by histological examination of the tissues and organs for evidence of rubella embryopathy ; therefore the aetiology of the condition remains speculative.

The associated abnormalities described in the case reports do not include the defects described in our patient. Schmit (1893) found the trachea connected to the oesophagus and a bony abnormality in the neck; there was an accessory spleen in the patient described by Tuynman and Gardner (1952). The cardiac malformations are essentially the same in all cases in that the pulmonary artery, having arisen normally, then joins the aorta at the site of the normal ductus arteriosus and fails to divide into its main branches.

The pathway by which the blood returns from the lungs to the left atrium appears to vary. The 
left atrium may receive no vessels (Schmidt, 1893 ; Allen and Affelbach, 1925) whereas Claireaux and Ferreira (1958) found an anomalous left superior vena cava and in Tuynman's and Gardner's (1952) patient the left atrium received the inferior vena cava. Our child resembles the first two in that no pulmonary or other venous return to the left atrium was defined and there was a large foramen ovale.

The oesophagus and respiratory tract are derived embryologically from the primitive foregut so that it is understandable that malformations of the two should be closely allied. At the end of the fourth week a slit-like groove appears in the ventral wall of the foregut just cephalad to the oesophagus. Willis (1958) describes how the pulmonary groove is reduced in length from behind forwards by growth and fusion of the lateral lips to separate the lumina of the trachea and infraglottic larynx from the oesophagus.

The presence of micrognathia and microstomia in our patient has implications with regard to the timing of the developmental defect. When the lung buds appear, only the first two pharyngeal arches are present (Hamilton, Boyd and Mossman, 1966). Micrognathia and microstomia are components of what McKenzie and Craig (1955) synthesized as 'the first arch syndrome', again the obvious aetiological link being a defect or anomaly in fetal vascular development. As far back as 1917, Ellis suggested that rather than defects of the heart and great vessels being secondary to the failure of development of the lungs they are in fact the primary lesion, and pulmonary agenesis is the result. This concept is supported by our patient whose three developmental defects can be attributed to fetal vascular abnormalities at the time of development of the pharyngeal arches from the foregut.
Various authors have pointed out the genetic background in the first arch syndrome. Booth and Berry (1967), in an extensive review of unilateral pulmonary agenesis, remarked on the high incidence of ipsilateral facial and jaw abnormalities. McKenzie and Craig (1955) suggest that there is a genetic predisposition to maldevelopment or suppression of some part of the arteries derived from the first arch and that the gene involved has a dominant character with variable specificity and expressivity with only a moderate degree of penetrance. We noted micrognathia in the father of our patient, although three living siblings showed no evidence of the first arch syndrome or of pulmonary-vascular abnormalities.

This child's initial respiratory efforts did not allow us to make the diagnosis in life.

\section{REFERENCES}

Allen, and Affelbach (1925). Congenital absence of both lungs. Surgery, Gynecology and Obstetrics, 41, 375.

Booth, J. B., and Berry, C. L. (1967). Unilateral pulmonary agenesis. Archives of Diseases in Childhood, 42, 361.

Claireaux, A. E., and Ferreira, H. P. (1958). Bilateral pulmonary agenesis. Archives of Diseases in Childhood, 33, 364.

Ellis, A. G. (1917). Congenital absence of lung. American Journal of Medical Science, 154, 33.

Hamilton, W. J., Boyd, J. D., and Mossman, H. W. (1966) Human Embryology, 3rd (revised) edition. Heffer, Cambridge.

McKenzie, J., and Craig, J. (1955). Mandibulo-facial dysostosis (Treacher Collins Syndrome). Archives of Diseases in Childhood, 30, 391.

Schmit, H. (1893). Ein Fall von vollständiger Agenesie bei der Lungen. Virchows Archiv für pathologische Anatomie und Physiologie und für klinische Medizin, 134, 25.

Tuynman, P. E., and Gardner, L. W. (1952). Bilateral aplasia of the lung. Archives of Pathology, 54, 306.

Willis, R. A. (1958). The Borderland of Embryology and Pathology. Butterworths, London.

Address for reprints: Box 5623, Boroko, T.P.N.G. 